\title{
年 \\ Re: The effect of urethroplasty surgery on erectile and orgasmic functions: a prospective study
}

\author{
Michael S. Floyd Jr. ${ }^{1}$, Ahmad M. Omar ${ }^{1}$, Andrew D. Baird ${ }^{2}$, Paul C. B. Anderson ${ }^{3}$ \\ ${ }^{1}$ Department of Reconstructive Urology, St Helens \& Knowsley Hospital NHS Trust, Whiston Hospital, \\ Warrington Road, Liverpool, United Kingdom; ${ }^{2}$ Department of Reconstructive Urology, Aintree University \\ Hospital Lower Lane, Aintree, Liverpool, , United Kingdom; ${ }^{3}$ Department of Genitourethral Reconstruction, \\ Russell's Hall Hospital Pensnett Road, Dudley, West Midlands, United Kingdom
}

To the editor,

We read with interest the recent paper by Urkmez et al examining the effects of urethroplasty on erectile and orgasmic function (1).

The authors report a prospective study involving 60 males who underwent buccal graft substitution, penile skin flap or anastomotic urethroplasty by a single surgeon and report the outcomes on both erectile and orgasmic function using the international index of erectile function (IIEF) score.

The authors conclude by stating that urethroplasty does not affect erectile, sexual or orgasmic function irrespective of surgery type, stricture location or length but acknowledge the limitations of the study including the lack of validated questionnaires.

This study does highlight one of the challenges for urethral surgeons: measuring sexual outcomes following urethroplasty. As endoscopic management of recurrent stricture disease moves towards formal urethroplasty with better long term success rates, assessing outcomes remains paramount from a patient and surgical perspective. To date, there have been limited attempts at developing specific patient reported outcomes (PROMS) for anterior urethral reconstruction (2). The first study performed to evaluate urethroplasty outcomes with a validated PROM did not assess sexual or erectile function (3). There remains a paucity of validated questionnaires available to the urethral surgeon to assess sexual function post urethroplasty. The IIEF and its short form are widely used to assess all aspects of sexual function but are not specific for urethral stricture disease and the short form does not evaluate ejaculation (4). Coursey et al evaluated sexual function after urethroplasty in 200 patients with a validated PROM and found a 30\% rate of erectile dissatisfaction based on type of urethroplasty with higher rates noted in the penile flap cohort, but concluded that the rate was similar to those who underwent circumcision (5). The Brief Male Sexual Function inventory (BMSFI) was developed as an assessment tool for male sexual health but is not specific for urethral stricture disease (6). The Men's Health Sexual Questionnaire (MHSQ) is a validated questionnaire (7) and has been employed to assess ejaculatory function following urethroplasty (8) but again is not urethral stricture specific. Patel et al have specifically employed the MHSQ ejaculatory domain to assess sexual function following buccal graft for staged penile urethroplasty and reported minimal differences in erectile and ejaculatory function but reported definite changes in penile curvature, length and sensitivity (9). Barbagli et al. have developed a non validated PROM to assess the effect of bulbar 
urethroplasty on sexual function and reported no erectile dysfunction post operatively but $23 \%$ of patients studied reported ejaculatory dysfunction (10).

Historically, a successful outcome following urethroplasty was based on the need for secondary intervention to improve outflow symptoms but outcomes should be all inclusive and evaluate psychological, voiding and sexual outcomes as well as quality of life with a specific, validated questionnaire.

Breyer et al have published preliminary data on the development of a patient specific outcome measure, the 32 item Urethral Stricture Symptoms and Impact Measure (USSIM), which will further address both voiding and sexual symptoms following urethroplasty $(1,11)$.

Undoubtedly, as the assessment (12) of urethral stricture disease becomes more elaborate measuring all outcomes following urethroplasty will become routine practice for those Urologists offering urethral reconstruction. The authors are to be commended on highlighting the lack of validated questionnaires currently available to those working in the field of urethroplasty.

Yours Sincerely,

Authors

\section{CONFLICT OF INTEREST}

None declared.

\section{REFERENCES}

1. Urkmez A, Yuksel OH, Ozsoy E, Topaktas R, Sahin A, Koca 0 , et al. The effect of urethroplasty surgery on erectile and orgasmic functions: a prospective study. Int Braz J Urol. 2018;44. [Epub ahead of print]

2. Baradaran N, Hampson LA, Edwards TC, Voelzke BB, Breyer BN. Patient-Reported Outcome Measures in Urethral Reconstruction. Curr Urol Rep. 2018;19:48.

3. Jackson MJ, Chaudhury I, Mangera A, Brett A, Watkin N, Chapple $C R$, et al. A prospective patient-centred evaluation of urethroplasty for anterior urethral stricture using a validated patient-reported outcome measure. Eur Urol. 2013;64:777-82.

4. Rosen RC, Riley A, Wagner G, Osterloh IH, Kirkpatrick J, Mishra A. The international index of erectile function (IIEF): a multidimensional scale for assessment of erectile dysfunction. Urology. 1997;49:822-30.
5. Coursey JW, Morey AF, McAninch JW, Summerton DJ, Secrest $\mathrm{C}$, White $\mathrm{P}$, et al. Erectile function after anterior urethroplasty. J Urol. 2001;166:2273-6.

6. O'Leary MP, Fowler FJ, Lenderking WR, Barber B, Sagnier PP, Guess HA, et al. A brief male sexual function inventory for urology. Urology. 1995;46:697-706.

7. Rosen RC, Catania J, Pollack L, Althof S, O'Leary M, Seftel AD. Male Sexual Health Questionnaire (MSHQ): scale development and psychometric validation. Urology. 2004;64:777-82

8. Erickson BA, Granieri MA, Meeks JJ, Cashy JP, Gonzalez CM. Prospective analysis of erectile dysfunction after anterior urethroplasty: incidence and recovery of function. $J$ Urol. 2010;183:657-61.

9. Patel DP, Elliott SP, Voelzke BB, Erickson BA, McClung CD, Presson AP, et al. Patient-Reported Sexual Function After Staged Penile Urethroplasty. Urology. 2015;86:395-400. 
10. Barbagli G, De Angelis M, Romano G, Lazzeri M. Long-term followup of bulbar end-to-end anastomosis: a retrospective analysis of 153 patients in a single center experience. J Urol. 2007;178:2470-3.

11. Breyer BN, Edwards TC, Patrick DL, Voelzke BB. Comprehensive Qualitative Assessment of Urethral Stricture Disease: Toward the Development of a Patient Centered Outcome Measure. J Urol. 2017;198:1113-8.

12. Chen L, Hou R, Feng C, Zhang X, Li D, Chen J, Hu B. Establishment of the U.L.T.R.A. measurement rating system for anterior urethral stricture. Int Urol Nephrol. 2017;49:1201-7.

\section{Correspondence address:} Michael S. Floyd Jr. Department of Reconstructive Urology, St Helens \& KnowsleyTeaching Hospitals NHS Trust Warrington Road Whiston Merseyside Prescot L35 5DR United Kingdom of Great Britain and Northern Ireland E-mail: nilbury@gmail.com

ARTICLE INFO

Michael S. Floyd Jr http://orcid.org/0000-0001-7229-3357

Int Braz J Urol. 2019; 45: 412-4

Submitted for publication: November 20, 2018

Accepted after revision: December 10, 2018

Published as Ahead of Print: February 10, 2019 